and several important research projects, in which juniors are invited to participate, are ongoing at present. Paramedical rotations-to gain experience in psychology, physiotherapy, etc.-are, of course, always available in a large centre such as ours.

Our deficiencies are thus not those of will, motivation or of expertise. However, we do need the support and encouragement of our academic mentors in Regional and College committees. Suffice it to say that our trainees are officially in limbo at present, because most of the mental handicap clinical tutorships in this Region have been put in abeyance. Unlike our general psychiatric colleagues, who retain their tutorships despite their own deficiencies, our Cinderella sub-specialty has been officially de-academized, unfortunately without consultation with either the trainees or their tutors. Our two senior registrar posts are presently being dismantled, with resultant loss of irreplaceable teaching material to future generations of trainees.

To conclude, if the trainee is hungry for knowledge, there are always ample opportunities for learning.

H. G. KINNELL

Botleys Park Hospital

Chertsey, Surrey

\section{Issues involved in work of child psychiatrists}

DeAR SIRS

The recent appearance of papers on child psychiatry presenting (a) the issues involved in the work of child psychiatrists (Gath, 1982) and (b) the apportionment of their time in various activities (Black and Black, 1982) acted as an invitation to us to present the work of the Working Party of Child Psychiatrists in the West Midlands region which has looked into these particular questions.

We were stirred into action by the realization of the enormity of differences in (a) facilities available; (b) settings in which we find ourselves working; and (c) individual preferences in method by which we meet the demands made upon us. In the same way as Black and Black (1982), we ascertained that 'present methods of collecting statistics by patient attendance only is seriously misrepresenting the volume and scope of the work done by consultant child psychiatrists.'

We decided to devise an instrument which would make it possible for all of us, independent of circumstances and choice, to record what we are actually doing, as well as where it is done and who we are doing it with. We feel the instrument is sufficiently tested and take the opportunity of presenting it to the membership of the profession through your correspondence columns, inviting its general use and the membership's comments and support in having it incorporated in the DHSS data-gathering machinery. To that effect we have sent a copy to the group in the Körner Committee which is looking into community services, pointing out that with small modifications it could be used by the other specialties with a community element (general psychiatry, geriatrics, psychogeriatrics).

Apart from the intrinsic benefit of making our statistical returns meaningful and representative, we also believe that the widespread use of this instrument could help the College to formulate both optimal and minimal requirements for facilities needed by consultant child psychiatrists and be the basis for planning resource developments at local level.

Since space limitations prohibit the presentation of the instrument, a brief description follows. Part I describes work with out-patients, distinguishing in terms of where it is done, whether in hospitals, other Health Authority establishments, educational establishments, Social Services establishments or patients' homes, taking account of all its components (direct clinical work, supervision, training or teaching, administration, research and travelling). Part II concerns in-patients in terms of bed availability, bed occupancy, etc. Part III describes the service in terms of population served, physical space, staffing, sources of referral and length of waiting-list. Instructions for its use have been prepared. Requests for copies should be addressed to the undersigned.

\section{Child Guidance Centre \\ North Avenue \\ Stoke Park}

A. Ambelas

Coventry $\mathrm{CV} 2$ 4DH

\section{REPERENCES}

GATH, A. (1982) Child and Adolescent Psychiatry Section: Issues in 1981. Bulletin, May, 6, 84-85.

BLACK, D. \& BLACK, M. (1982) The use of consultant time in child psychiatry. Bulletin, July, 6, 116-17.

*A committee set up by the DHSS to report on the more effective method of data collecting. 